\title{
Kinetic Characterization of a Panel of High-Affinity Monoclonal Antibodies Targeting Ricin and Recombinant Re-Formatting for Biosensor Applications
}

\author{
Michelle Cummins ${ }^{1,3}$, Con Dogovski ${ }^{2,4}$, Remy Robert ${ }^{1,5}$, Malcolm Alderton ${ }^{2}$, Damien Chong ${ }^{2}$, \\ David Proll ${ }^{2}$, Luisa Pontes-Braz ${ }^{1}$, Anna Raicevic ${ }^{1}$, Meghan Hattarki ${ }^{1}$, Stewart Nuttall ${ }^{1}$ and \\ Olan Dolezal ${ }^{1, *}$ \\ 1 CSIRO Materials Science and Engineering, Parkville, Victoria 3052, Australia \\ 2 Defense Science and Technology Organization, Fishermans Bend, Victoria 3207, Australia \\ 3 The School of Medicine, Deakin University, Waurn Ponds, Victoria 3216, Australia \\ 4 Bio21 Institute, The University of Melbourne, Parkville, Victoria 3052, Australia \\ 5 The Department of Immunology, Monash University, Clayton, Victoria 3800, Australia \\ * Author to whom correspondence should be addressed, E-Mail: Olan.Dolezal@csiro.au; \\ Tel.: +613-9662-7229.
}

Received: 19 February 2014; in revised form: 10 April 2014 / Accepted: 28 April 2014 /

Published: 9 May 2014

\begin{abstract}
Ricin is a potent glycoprotein toxin that is structurally composed of two subunits joined via a disulfide bond: a $\sim 30 \mathrm{kDa}$ subunit $\mathrm{A}$ (RTA) and a $\sim 32 \mathrm{kDa}$ subunit $\mathrm{B}$ (RTB). There are fears of ricin being used as a weapon for warfare and terrorism and, as such, there is an increasing need for the development of immunodiagnostic reagents targeted towards this toxin. This article describes the production and characterization of a panel of six ricinspecific monoclonal IgG antibodies (mAbs), previously selected based upon their ability to inhibit ricin-mediated killing of cultured cells. Subsequent epitope binding analysis using the surface plasmon resonance (SPR) array biosensor (ProteOn XPR36) indicated three distinct, non-competitive binding epitopes ("bins"). The association $\left(\mathrm{k}_{\mathrm{a}}\right)$ and dissociation $\left(\mathrm{k}_{\mathrm{d}}\right)$ rate constants and binding affinities $\left(\mathrm{K}_{\mathrm{D}}\right)$ of each of the mAbs to ricin were also determined by SPR using Biacore T100 instrument. Affinities $\left(K_{D}\right)$ ranged from $0.1 \mathrm{nM}$ to $9 \mathrm{nM}$. We present the coding sequences of the variable domains of the six $\mathrm{mAbs}$, the expression, kinetic and cytotoxicity assays for two recombinant Fab (rFab) fragments and demonstrate a rFab affinity improvement by chain-shuffling. Together, these antibodies and constituent $\mathrm{rFabs}$ represent a panel of reagents for high-affinity recognition of ricin with potential national security biosensor applications.
\end{abstract}


Keywords: monoclonal antibody; ricin; Fab fragment; SPR; epitope binning

\section{Introduction}

Ricin toxin (RT) is a glycoprotein, produced by the castor bean plant Ricinus communis, which since its discovery in the 1880 s has been extensively studied in both medical and basic research [1,2]. With a mouse $\mathrm{LD}_{50}$ of $10-18 \mu \mathrm{g} / \mathrm{kg}$ it represents a highly toxic compound that can be readily extracted from castor oil plant seeds [2]. Structurally, the toxin is composed of a $\sim 30 \mathrm{kDa}$ A subunit (RTA) and a $\sim 32 \mathrm{kDa} B$ subunit (RTB) that are covalently linked via an intermolecular disulfide bond [3]. The A subunit is an RNA N-glycosidase that functions to inactivate eukaryotic ribosomes. The B subunit binds to glycoproteins and glycolipids containing $\beta(1-3)$-linked galactose of $\mathrm{N}$-acetaylgalactosamine residues [4] and mediates attachment of RT to the surface of eukaryotic cells [5]. Once bound, RT is internalized by endocytosis and is trafficked to the endoplasmic reticulum (ER) by vesicular retrograde transport [6,7]. The RTA-RTB heterodimer itself is not active [8], however, upon entering the ER, the disulphide bond which tethers the two subunits is reduced and liberates the enzymatically active form of the A subunit. The A subunit is then transported across the ER membrane into the cytosol where it selectively depurinates a highly conserved adenine residue in the sarcin/ricin loop of 28S rRNA. This results in inactivation of cellular ribosomes, arrest of protein synthesis $[9,10]$ and causes cell death.

Ricin is considered a significant threat in western countries as there is a real potential for the toxin to be used as a weapon for biowarfare and terrorism [11]. This has raised considerable unease in the biosecurity community and consequently the United States Government's Centres for Disease Control and Prevention (CDC) categorizes ricin as a class B toxin whilst the Australian Government's Department of Health and Ageing classifies ricin as a Tier 1 Security Sensitive Biological Agent (SSBA). Most concern lies with the ease with which ricin can be isolated from castor beans, its inherent stability, potency and the lack of treatment options for intoxicated individuals [12,13]. Efforts to counter this threat have focused on the development of potential vaccines and neutralizing antibodies. These included the recombinant derivative of RTA RiVax [13,14], the GD12 monoclonal antibody [15], the combinatorial use of three monoclonal antibodies (RB34, RB37 and RA36) [16] and the more recent development of a humanized neutralizing anti-ricin antibody hD9 [17]. Beyond vaccination, there is also a requirement for the development of ricin detection reagents for use in national security applications and possibly for rapid treatment of ricin intoxication. Antibody-based systems remain the "gold standard" amongst detection technologies [18]. Such platforms are generally robust, reliable, display high-specificity and high sensitivity. These systems may also incorporate smaller antibody-derived fragments, such as Fab fragments, that retain the targeting specificity of whole mAbs, whilst having the added advantage of possessing improved size:binding ratios and lower production costs [19]. Pelat et al. [20] has reported on the generation and characterization of phage library-derived human single-chain Fv ( $\mathrm{scFv}$ ) fragments with the capacity to neutralize biological activity of ricin. Similarly Anderson et al. [21,22] and Walper et al. [23] have generated and characterized phage-library derived single-domain antibodies (sdAbs) against RTA and RTB. 
Dertzbaugh et al. [24] and Tran et al. [25] have described the generation and properties of a panel of monoclonal antibodies with affinity to ricin. The antibodies were selected on their ability to bind ricin in ELISA-based bioassays and/or inhibition of ricin-mediated eukaryotic cell cytotoxicity in vitro. In this study, we have further characterized a subset of these mAbs. Specifically, we have performed epitope binning experiments and determined binding rate and affinity constants. In addition, we have cloned and expressed recombinant Fabs for some of these mAbs, thus allowing for sequence-based comparison of antigen-binding paratopes and the development of a suite of reagents for incorporation into biosensor and other advanced assays.

\section{Results and Discussion}

\subsection{Production and Characterization of a Panel of Six Anti-Ricin mAbs}

From a panel of previously described mAbs targeting ricin, six mAbs (9C3, 11D7, 14F11, 15C5, $7 \mathrm{G} 12$ and 8G2) were selected on the basis of preliminary epitope mapping data [24,25]. In particular, we aimed to analyze these antibodies in terms of their biophysical properties and their suitability as detection reagents. To provide sufficient quantities of reagents for biosensor testing and down-stream characterization, scale-up production of the six mAbs from the serum-free medium was performed. Affinity chromatography on protein A and size exclusion chromatography was utilized for the subsequent purification from serum-free cultures (data not shown).

\subsection{Epitope Binding Analysis of $m A b s$}

The specificities and binding characteristics of the purified mAbs were examined using surface plasmon resonance (SPR) measurements. Initially, the ProteOn XPR36 SPR instrument was utilized for epitope binning experiments. Taking advantage of ProteOn's multiplexing capability, a $6 \times 6$ antibody-ricin sandwich assay was performed simultaneously. Thus, all six mAbs were immobilized on a GLC chip in the vertical direction. After binding of ricin to this panel (Figure 1A, top panels), the same set of mAbs was injected across the 6 channels in the horizontal direction and binding profiles examined (Figure 1A, bottom panels). For this experimental setup, which is analogous to a sandwich ELISA where the immobilized and injected $\mathrm{mAbs}$ are identical, no binding was expected as the ricin epitope for this $\mathrm{mAb}$ is already occupied. For example, of the mAbs screened with $14 \mathrm{~F} 11$ as the primary (immobilized) antibody, only 11D7 and 7G12 still bound ricin, indicating distinct epitopes. Conversely, when the first antibody captured was 11D7 all subsequent mAbs (except 8G2) retained the ability to recognize the bound ricin. An interesting result observed during these experiments was a weak binding signal obtained when $7 \mathrm{G} 12 \mathrm{mAb}$ was passed over 7G12-ricin complex (Figure 1A, bottom right panel). Control injection experiment where $7 \mathrm{G} 12 \mathrm{mAb}$ was shown not to bind to itself or to the chip surface (data not shown) further suggested that 7G12 mAbs may, in fact, recognize a second epitope on ricin surface, albeit with a weak affinity. Unlike for other five mAbs, ricin did not bind to immobilized $8 \mathrm{G} 2$ (Figure 1A, top left panel) suggesting that immobilization of $8 \mathrm{G} 2 \mathrm{mAb}$ onto the chip surface destroyed its binding capacity. However, no binding of $8 \mathrm{G} 2 \mathrm{mAb}$ was also observed when ricin was captured via other five mAbs (Figure 1A, bottom panels). Western blot analysis and ELISA with ricin coated to solid support, however, showed that $8 \mathrm{G} 2 \mathrm{mAb}$ bound to ricin and RTA 
(data not shown). Although not easily explicable, our findings were consistent with those of Dertzbaugh et al. [24] who showed that 8G2 IgG did not bind ricin in ELISA capture format, but bound to ricin on immunoblots or when directly coated to a solid support. These results indicated that the $8 \mathrm{G} 2$ may not recognize native form of ricin that is required for SPR assays. Furthermore, it is not unusual that selection of monoclonal antibody clones using plastic-adsorbed antigens (in ELISA wells) can result in selection of mAbs against denatured forms [26]. Using this approach, three distinct bins were detected on ricin with 15C5, 9C3 and 14F11 mAbs belonging to one such bin while 11D7 and 7G12 belonged to two separate bins (Figure 1B). Epitope binning analysis also allowed us to assess the capacity of these mAbs to be used both as a capture reagent when bound to the solid phase and as a detection reagent after the antigen was captured.

Figure 1. Summary of epitope-binning analysis of ricin mAbs using ProteOn XPR36 instrument. (A) Ricin solution $(50 \mathrm{nM})$ was injected (injection points are indicated with arrows) over immobilized mAbs (upper panels). All six mAbs (100 nM) were then injected over $\mathrm{mAb}+$ ricin complex (lower panels, $\mathrm{mAb}$ injection points are indicated with arrows) and their binding to captured ricin was assessed; (B) The reactivity pattern matrix obtained in binning analysis. At least three distinct epitopes were observed. Monoclonal antibodies 7G12 and 11D7 bind two separate distinct epitopes whilst the third epitope is defined by mAbs 9C3, 14F11 and 15C5. 8G2 did not bind ricin in either orientation.

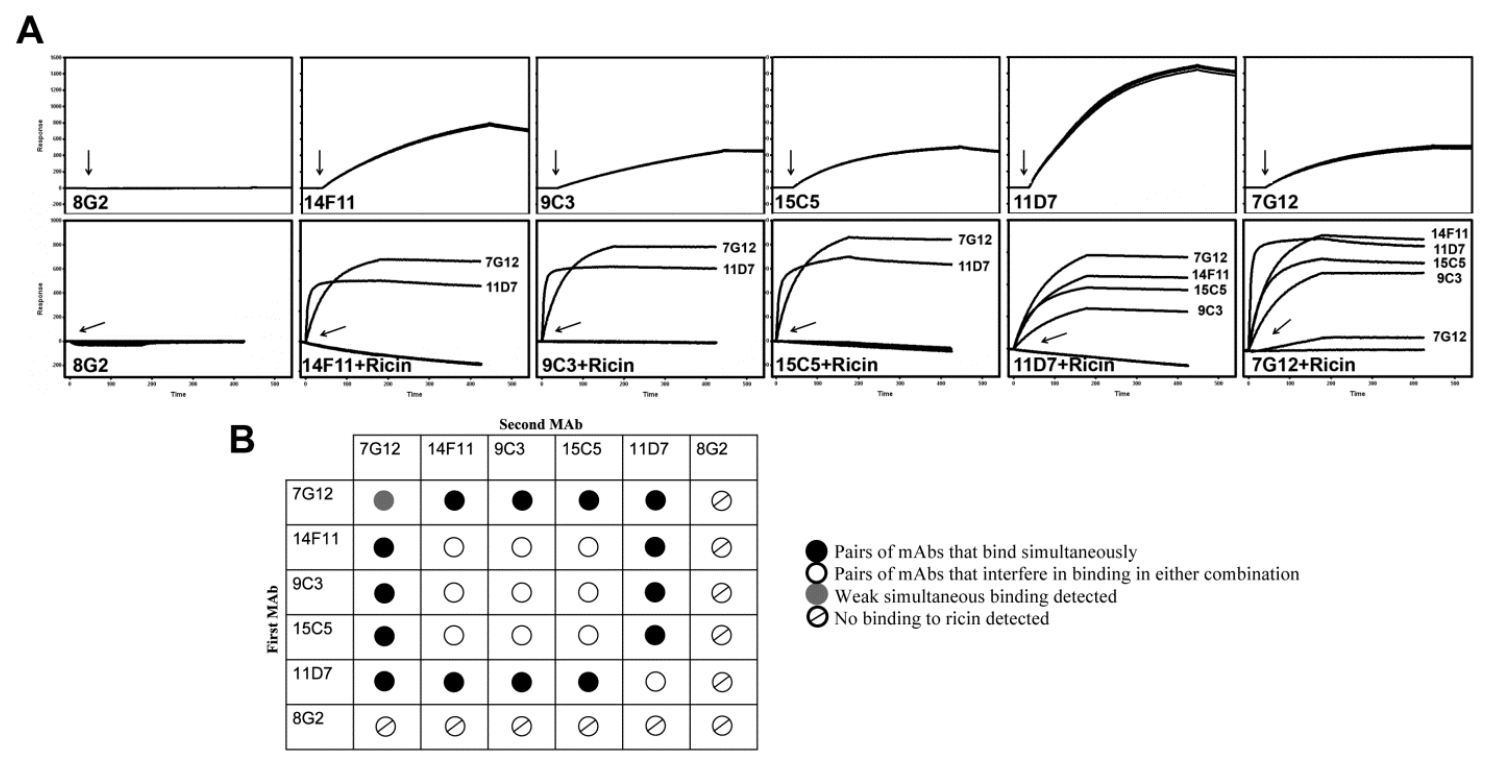

\subsection{Kinetic Analysis of $m A b s$}

To more precisely dissect the kinetics of the mAb-ricin interactions, kinetic analysis was performed using a Biacore T100. Similar to results achieved with the ProteOn XPR36 instrument, no binding of ricin to $8 \mathrm{G} 2$ was detected, while the other five mAbs all bound ricin (Figure 2). The association $\left(\mathrm{k}_{\mathrm{a}}\right)$ and dissociation $\left(\mathrm{k}_{\mathrm{d}}\right)$ rate constants and the corresponding equilibrium dissociation constants $\left(\mathrm{K}_{\mathrm{D}}\right)$ determined for the mAbs interacting with whole toxin (RT), ricin subunit B (RTB) and ricin subunit A (RTA) are presented in Table 1. Affinities $\left(\mathrm{K}_{\mathrm{D}}\right)$ for ricin ranged from $0.15 \mathrm{nM}$ to $8.9 \mathrm{nM}(7 \mathrm{G} 12>9 \mathrm{C} 3$ and $11 \mathrm{D} 7>15 \mathrm{C} 5>14 \mathrm{~F} 11)$ placing these antibodies in the desired high-affinity bracket for 
biological and sensor applications. These SPR results further confirmed preliminary binning results of Dertzbaugh et al. [24] which indicated that four of these mAbs (9C3, 11D7, 15C5 and 14F11) bind to RTB whilst 7G12 binds to RTA. Interestingly, 7G12 mAb also showed minor yet reproducible binding interaction with RTB (Figure 2, bottom right panel). Taken together with the results obtained in epitope binning experiments (Figure 1A, bottom right panel) it is possible that this minor interaction occurs as a result of lectin part of ricin (B-chain) interacting with $\mathrm{mAb}$ associated glycans. To evaluate this speculation, additional SPR measurements of mAb-ricin interactions with galactose supplemented in the SPR binding buffer as a blocking agent would have to be carried out.

Figure 2. Binding kinetics for ricin interacting with captured mAbs on the chip surface, ricin $=\mathrm{RT}$ (left panels), ricin subunit $\mathrm{A}=\mathrm{RTA}$ (middle panels) and ricin subunit $\mathrm{B}=\mathrm{RTB}$ (right panels). (A) 14F11; (B) 9C3 (C) 11D7; (D) 15C5 and (E) 7G12. The analytes were injected over captured mAbs at a flow rate of $30 \mu \mathrm{L} / \mathrm{min}$ for 240 -sc (RT) or 300-s (RTA and RTB). Data sets that gave a significant dose response were globally fit to a simple 1:1 binding model to obtain the kinetic parameters of the interaction. The black traces represent the experimental data whilst the orange traces represent the fit of a simple $1: 1$ interaction model to the data.

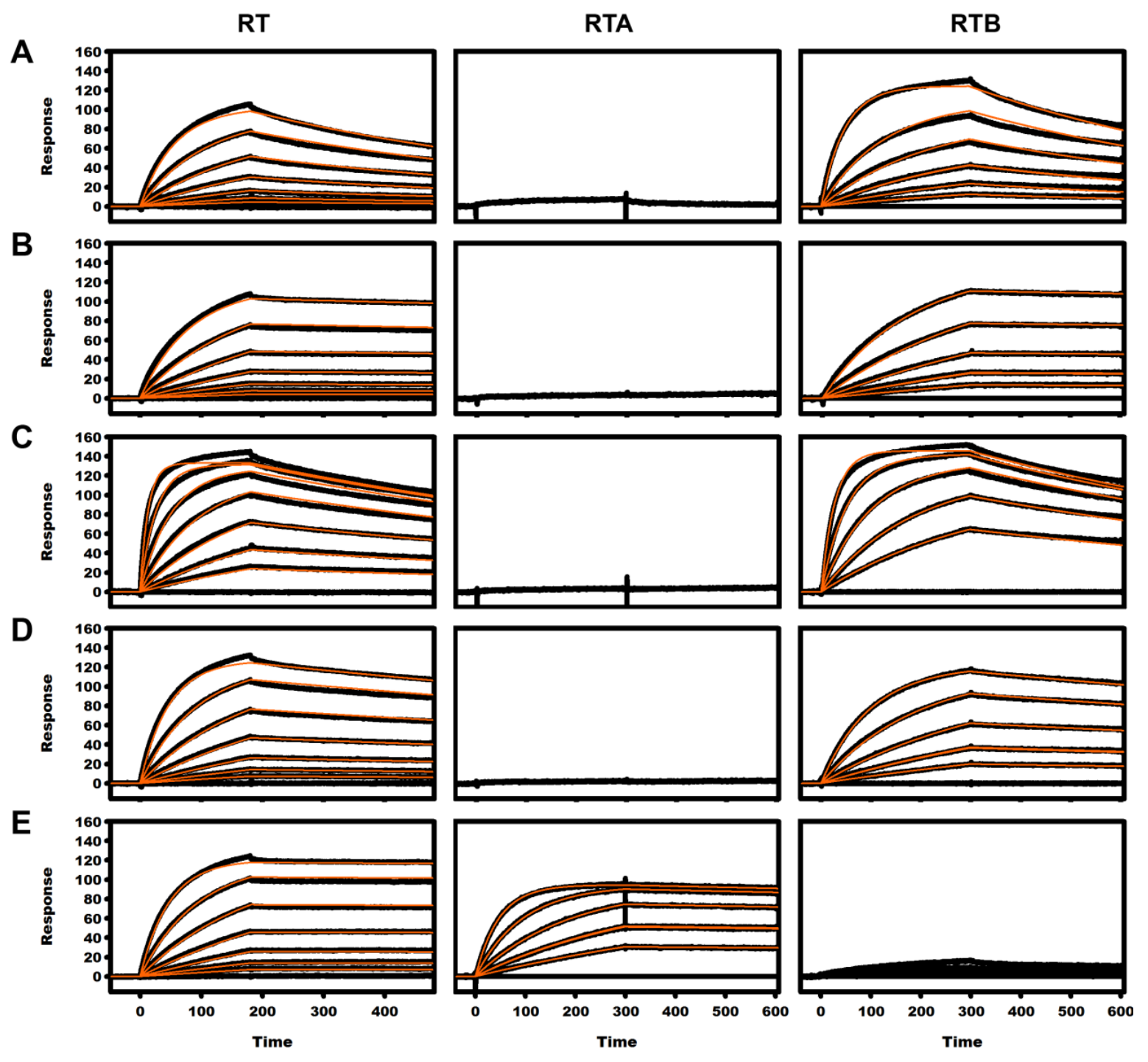


Table 1. Association and dissociation rate and equilibrium dissociation constants of mAbs interacting with ricin (RT: $n=3$ ), subunit A (RTA: $n=2$ ) and subunit B (RTB: $n=2$ ).

\begin{tabular}{|c|c|c|c|c|}
\hline mAb & Analyte & $\mathrm{k}_{\mathrm{a}} \times 10^{4}\left(\mathrm{M}^{-1} \mathrm{~s}^{-1}\right)$ & $k_{d} \times 10^{-4}\left(s^{-1}\right)$ & $K_{D}(n M)$ \\
\hline \multirow{2}{*}{$7 G 12$} & $\mathrm{RT}$ & $21.2 \pm 0.3$ & $0.30 \pm 0.17$ & $0.15 \pm 0.08$ \\
\hline & RTA & $64.7 \pm 6.6$ & $1.1 \pm 0.5$ & $0.13 \pm 0.2$ \\
\hline \multirow{2}{*}{$9 \mathrm{C3}$} & RT & $11.7 \pm 0.5$ & $1.5 \pm 0.1$ & $1.3 \pm 0.2$ \\
\hline & RTB & $14.0 \pm 0.5$ & $1.3 \pm 0.4$ & $0.9 \pm 0.3$ \\
\hline \multirow{2}{*}{ 11D7 } & $\mathrm{RT}$ & $74.0 \pm 1.8$ & $9.5 \pm 0.4$ & $1.3 \pm 0.1$ \\
\hline & RTB & $94 \pm 16$ & $9.2 \pm 0.2$ & $1.0 \pm 0.2$ \\
\hline \multirow{2}{*}{ 14F11 } & RT & $16.5 \pm 0.6$ & $14.5 \pm 0.9$ & $8.9 \pm 0.9$ \\
\hline & RTB & $18.0 \pm 1.3$ & $11.0 \pm 2.2$ & $6.0 \pm 0.7$ \\
\hline \multirow{2}{*}{$15 C 5$} & RT & $21.3 \pm 0.9$ & $5.0 \pm 0.3$ & $2.4 \pm 0.2$ \\
\hline & RTB & $24.0 \pm 2.8$ & $4.0 \pm 0.1$ & $1.7 \pm 0.1$ \\
\hline $8 G 2$ & RT/RTA & NBD & NBD & NBD \\
\hline
\end{tabular}

\subsection{Recombinant Fab Antibody Engineering}

The next step in obtaining a suite of reagents for biosensor applications was conversion of mAbs to a recombinant format. As an initial step, the antibody $\mathrm{V}_{\mathrm{H}}$ and $\mathrm{V}_{\mathrm{L}}$ domains were cloned and sequenced from hybridoma (parental) cell lines. Deduced amino acid sequences were consistent with experimentally determined N-terminal residues (data not shown), validating the identity of the antibody genes cloned. High sequence similarity ( $>90 \%)$ in both heavy and light chains was seen for mAbs 9C3, $14 \mathrm{~F} 11$ and $15 \mathrm{C} 5$, but less than $67 \%$ similarity for the heavy and light chains of 11D7, 7G12 and 8G2 (Figure 3). This further supported our interpretation of our epitope binning results which suggested that 9C3, 14F11 and 15C5 recognize the same epitope.

Figure 3. Sequence alignment of the mAb heavy and light chains. Alignment of heavy (A) and light (B) chain amino acid sequences using the Global-Reference alignment tool in Clone Manager 9. Like amino acids are represented by (.), gaps introduced into sequences to optimize alignment are represented by (-). CDR regions are labeled according to Kabat's nomenclature.

A

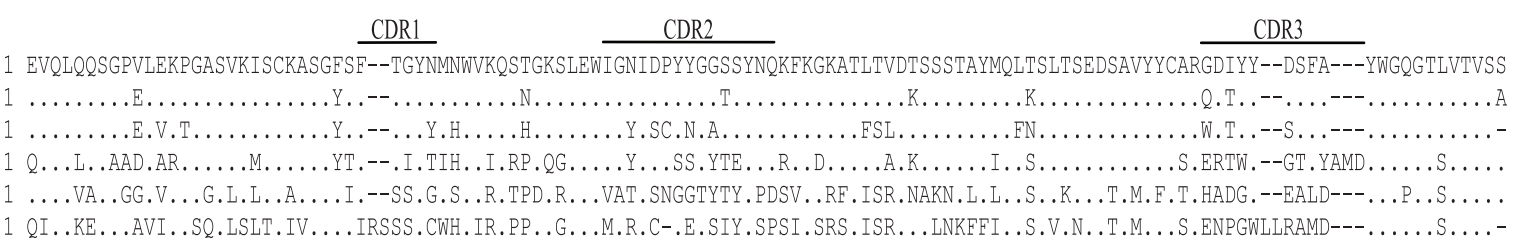

CDR1

CDR2 CDR3 1 DVVMTQTPLSLPVSLGDQASISCRSSQSLVHS-NGNTYLHWFLQKPGQSPKLLIFKVSHRESGVPDRFSGSGSGTDETLKISRVEAEDLGVYFCSQNTHVPPYTEGGGTKLEIKR

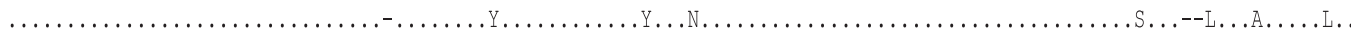

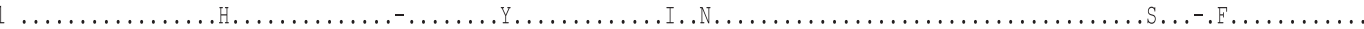

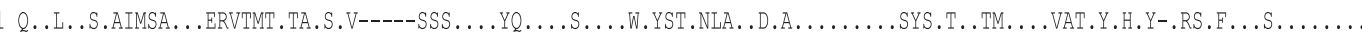

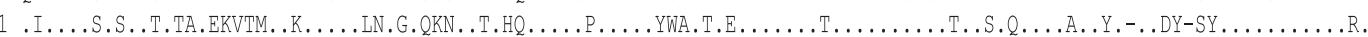

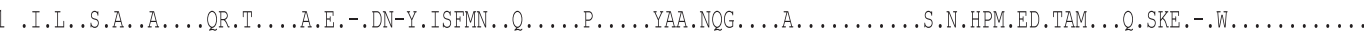


Recombinant Fab fragments for 9C3, 11D7, 14F11, 15C5, 7G12 and 8G2 were assembled, and expressed in E. coli (Figure 4). Poor bacterial expression was observed for 11D7, 15C5 and 7G12 rFabs and consequently these three constructs were not characterized any further. Recombinant Fab proteins $8 \mathrm{G} 2(8 \mathrm{G} 2 \mathrm{rFab}), 9 \mathrm{C} 3(9 \mathrm{C} 3 \mathrm{rFab})$ and 14F11 (14F11 rFab) were purified to homogeneity using a combination of $\mathrm{Ni}^{2+} / \mathrm{NTA}$ affinity and size exclusion chromatography. The final yield of purified $8 \mathrm{G} 2 \mathrm{rFab}$ and 14F11 rFab was approximately 5 times ( $0.5 \mathrm{mg}$ per liter of bacterial culture) higher than that of $9 \mathrm{C} 3 \mathrm{rFab}(0.1 \mathrm{mg} / \mathrm{L})$. SPR binding analysis of all three rFabs was performed using Biacore T100 kinetic experiments with ricin immobilized on the chip surface. As was the case with the parental $\mathrm{mAb}$, no binding to ricin was observed for $8 \mathrm{G} 2 \mathrm{rFab}$ (data not shown). Importantly, 14F11 and 9C3 rFab bound to ricin with similar binding profiles and affinity as their parental mAbs (Figure 5, Table 2). As established in the previous section, 14F11 and 9C3 mAbs bound to the same epitope, an unsurprising result given the high homology between the heavy and light chain sequences (92\% and $93 \%$ respectively, Figure 3).

Figure 4. Construction of the anti-ricin $\mathrm{rFab}$ in pGC (cloning cassette). Variable genes $\left(\mathrm{V}_{\mathrm{H}}\right.$ and $\mathrm{V}_{\mathrm{L}}$ ) were cloned into the $\mathrm{pGC/huchc1}$ vector preceded by a 5 'end pelB and OmpA signal sequences, respectively. A histidine tag and double FLAG tag sequences are 3' of the $\mathrm{V}_{\mathrm{H}} \mathrm{C}_{\mathrm{H} 1}$ and $\mathrm{V}_{\mathrm{L}} \mathrm{C}_{\mathrm{L}}$, respectively.

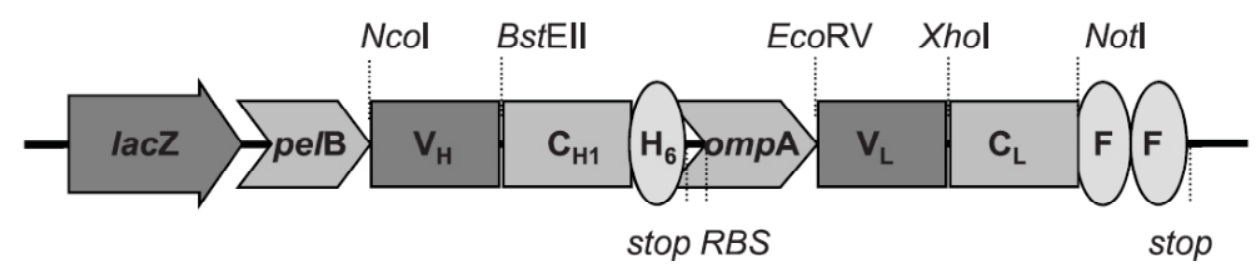

Figure 5. Classical kinetics of rFabs, (A) 14F11; (B) 9C3 and (C) chained-shuffled construct, binding to immobilized ricin. Recombinant Fabs, (concentrations of 0, $0.5 \mathrm{nM}, 2 \mathrm{nM}, 8 \mathrm{nM}$, $32 \mathrm{nM}$ and $128 \mathrm{nM}$ ) were sequentially injected for 420 -s at a flow rate of $30 \mu \mathrm{L} / \mathrm{min}$. In the case of the chained-shuffled construct, $64 \mathrm{nM}$ instead of $128 \mathrm{nM}$ top concentration was used. The dissociation phase of the complex was monitored for 900-s except for the highest concentration of chained-shuffled construct where the dissociation was monitored for 1800 -s. The black lines represent triplicate experimental data and the orange lines represent the fit to a simple 1:1 interaction model.

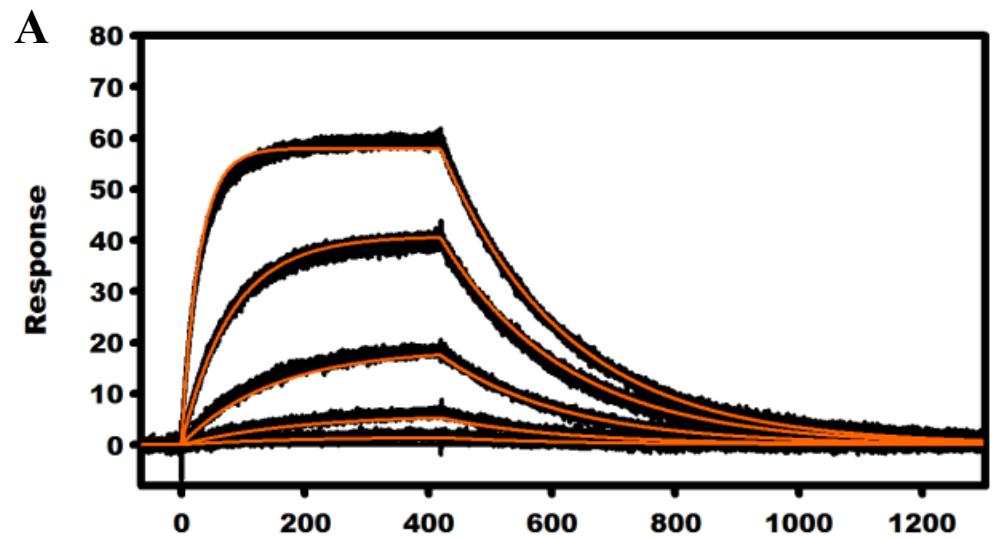


Figure 5. Cont.

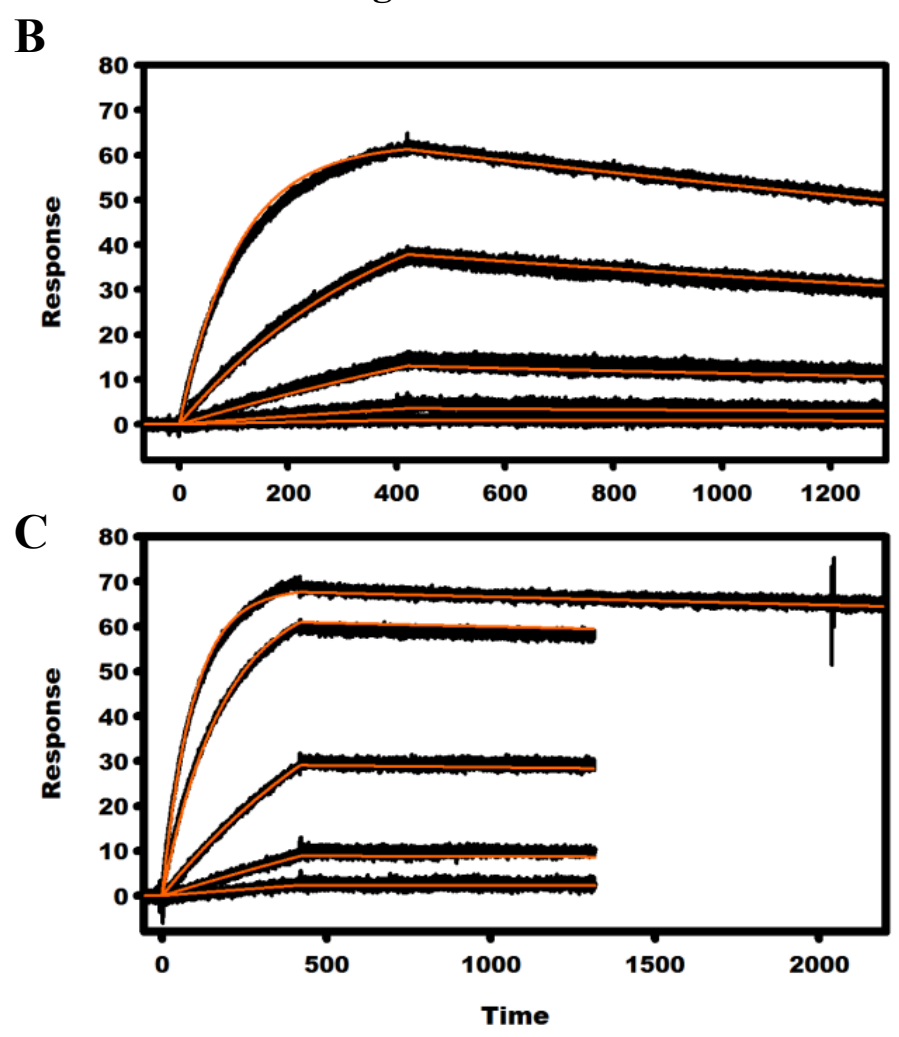

Table 2. Rate and equilibrium dissociation constants for rFabs binding to ricin $(n=3)$.

\begin{tabular}{cccc}
\hline $\mathbf{r F a b}$ & $\mathbf{k}_{\mathbf{a}} \times \mathbf{1 0}^{\mathbf{4}} \mathbf{( \mathbf { M } ^ { - \mathbf { 1 } } \mathbf { s } ^ { - \mathbf { 1 } } )}$ & $\mathbf{k}_{\mathbf{d}} \times \mathbf{1 0}^{-\mathbf{4}} \mathbf{( \mathbf { s } ^ { - \mathbf { 1 } } )}$ & $\mathbf{K}_{\mathbf{D}}(\mathbf{n M})$ \\
\hline $\mathbf{1 4 F 1 1}$ & $18.7 \pm 0.8$ & $50.0 \pm 0.1$ & $27.0 \pm 0.6$ \\
$\mathbf{9 C 3}$ & $9.9 \pm 0.5$ & $2.32 \pm 0.02$ & $2.3 \pm 0.1$ \\
Chained-shuffled & $23.4 \pm 0.5$ & $0.21 \pm 0.07$ & $0.13 \pm 0.02$ \\
\hline
\end{tabular}

To further engineer anti-ricin $\mathrm{rFab}$ fragment for higher affinity, a chain-shuffling strategy was employed whereby the 14F11 rFab light chain was replaced with the 9C3 rFab light chain. The rationale supporting this particular rearrangement was based on two observations: 1) E. coli expression levels were higher for the lower affinity construct (14F11), and 2) the difference in affinity between 14F11 and 9C3 could most likely be attributed to the sequence differences within the CDR3 region of the two light chains (Figure 3). Specifically we speculated that the most significant difference likely to affect affinity of the two rFabs was the double-proline insertion within CDR L3 of 9C3. Expression yields for the chained-shuffled $\mathrm{rFab}(14 \mathrm{~F} 11 \mathrm{H} / 9 \mathrm{C} 3 \mathrm{~L})$ were equivalent or better when compared with the parental 14F11 rFab. More importantly, when compared with 14F11 and 9C3 rFabs, the affinity of the chained-shuffled $\mathrm{rFab}$ to ricin was improved 208- and 18-fold respectively, an enhancement, predominantly due to favorable dissociation kinetics (Table 2, Figure 5).

\subsection{Antibody Neutralization of Ricin-Mediated Cytotoxicity Assays}

The ability of the three rFab fragments (9C3, 14F11, chain-shuffled) to inhibit ricin-mediated killing of small airway epithelial (SAE) cells in vitro was determined and compared with the parental mAbs (Figure 6). The chained-shuffled $\mathrm{rFab}$, showed the greatest protection of the three rFabs tested 
and was also superior to the $9 \mathrm{C} 3 \mathrm{mAb}$ which was shown by SPR to have greater than 10 -fold weaker affinity (Tables 1 and 2). We attributed this enhanced protection to the better binding kinetics and in particularly to the difference in dissociation rate constants. Thus, for example, the estimated $\mathrm{k}_{\mathrm{d}}$ in case of the chained-shuffled $\mathrm{rFab}\left(0.21 \times 10^{-4} \mathrm{~s}^{-1}\right)$ was 11-fold and 238-fold lower than in case of 9C3 $\mathrm{rFab}$ $\left(2.32 \times 10^{-4} \mathrm{~s}^{-1}\right)$ and $14 \mathrm{~F} 11 \mathrm{rFab}\left(50 \times 10^{-4} \mathrm{~s}^{-1}\right)$, respectively. Lower $\mathrm{k}_{\mathrm{d}}$ values make the antibody-ricin complex more stable and consequently decrease a chance of a ricin molecule detaching from the antibody and penetrating the cell membrane.

Figure 6. Antibody neutralization of ricin-mediated cellular cytotoxicity. Affinity-purified monoclonal antibody (mAb) was mixed with ricin toxin before incubation with small airway epithelial cells in culture. Cytotoxicity was determined using Neutral Red as a vital stain. The Absorbance at $540 \mathrm{~nm}$ was determined for each well and used to calculate cytotoxicity relative to an untreated control (\% Control). Means were normalized against cells treated with ricin only and expressed as a percentage of the negative control.

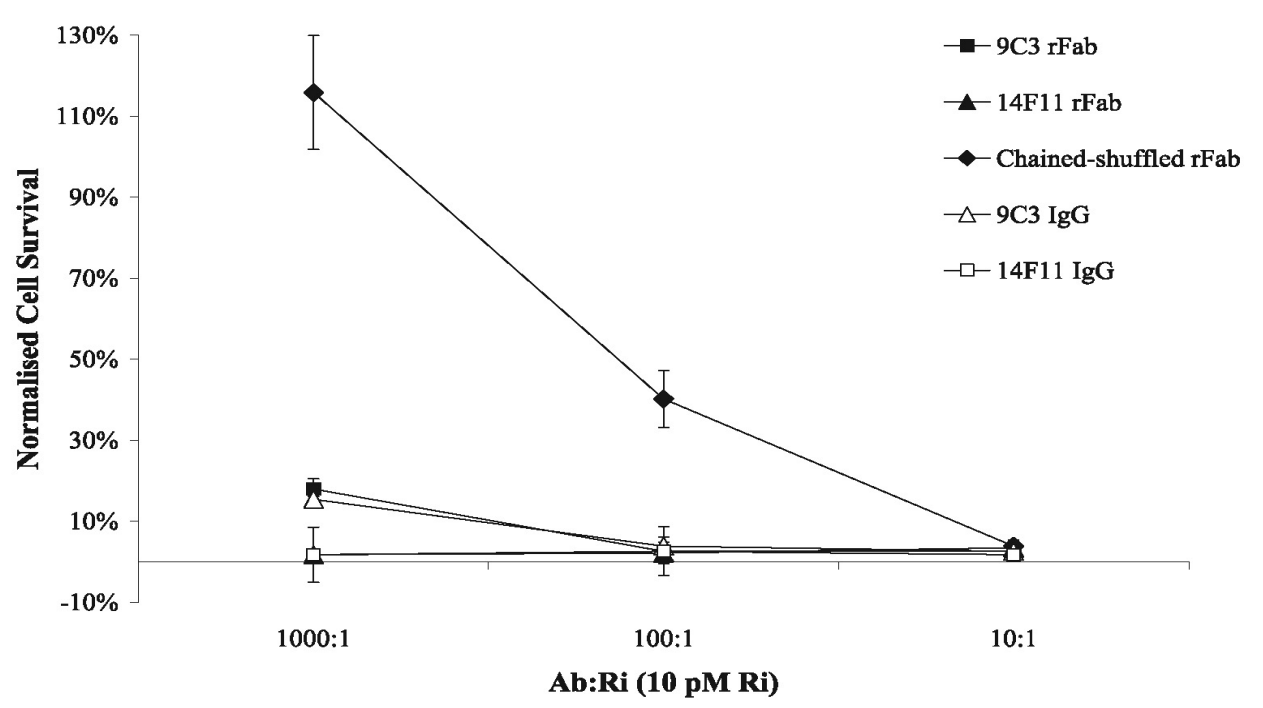

This study has provided a thorough dissection of binding kinetics for the five anti-ricin mAbs. We determined that mAbs 7G12 and 9C3 had the slowest dissociation rate while 11D7 had the fastest association rate. In a detection sensor format it is most practicable to utilize antibodies with slow dissociation for use as capture reagents, whilst non-competing mAbs with weaker affinities may then be employed as secondary reagents that bind and confirm the presence of captured ricin. Tran et al. [25] showed the potential of $7 \mathrm{G} 12 \mathrm{mAb}$ as a platform capture reagent for detection of ricin. The high affinity of this antibody for ricin allowed for the detection of ricin in both commercial preparations and environment samples using the Biacore X platform. In this study we have shown that 7G12 mAbs tight affinity for ricin is mainly driven by its slow dissociation rate thus making this mAb very-well suited as a capture reagent. Additionally, our work demonstrates the utility of four other mAbs in an SPR based ricin detection biosensor platforms. Thus, $14 \mathrm{~F} 11 \mathrm{mAb}$ is unlikely to be suitable as a capture agent, owing to its fast dissociation kinetics, yet it may suffice as a secondary reagent as slower dissociation would be enhanced as a result of its bivalent nature and this avidity effect may drive 
tighter binding. Nevertheless, given that 9C3 mAb binds the same epitope with greater affinity, it perhaps represents a preferable mAb for use as a capture or secondary detection reagent.

Recombinant antibody fragments such as Fabs, scFv and sdAbs are valuable alternatives to full length monoclonal antibodies for use in biosensor devices as they provide smaller, yet stable and highly specific reagents against the target antigen $[23,27]$. To further investigate the panel of six mAbs we have cloned variable heavy and light gene fragments and reformatted these as recombinant Fab fragments for expression in E. coli. Of these, only 8G2, 14F11 and 9C3 rFab were expressed at significant levels using standard expression conditions. More importantly, 9C3 and 14F11 rFabs bound ricin with near identical affinities as their parental mAbs. Considering the sequence similarity, we hypothesized that the difference in binding kinetics for these two rFabs could be attributed to the CDR3 region of the light chain. By combining the heavy chain of 14F11 rFab with the light chain of 9C3 $\mathrm{rFab}$, we generated a chained-shuffled $\mathrm{rFab}(14 \mathrm{~F} 11 \mathrm{H} / 9 \mathrm{C} 3 \mathrm{~L})$ with a significantly higher binding affinity for ricin. Figure 7 illustrates SPR sandwich assays for detection of ricin where $7 \mathrm{G} 12 \mathrm{mAb}$ is used for ricin capture and recombinant Fabs are used as secondary (detection) reagents. Results demonstrate that the slowly dissociating chain-shuffled and 9C3 rFab constructs perform better in the sandwich assay than the faster dissociating $14 \mathrm{~F} 11 \mathrm{rFab}$.

Figure 7. SPR sandwich assay for detection of ricin using 7G12 $\mathrm{mAb}$ for capture and rFabs as secondary detecting reagents. Four different assays (sensorgrams) are overlaid in the diagram. Step 1: Injection \& capture 7G12 mAb onto a CM5 chip surface containing rabbit anti-mouse IgG, Fc specific polyclonal antibody; Step 2: Injection and binding of ricin (at $100 \mathrm{nM}$ ) to captured 7G12 mAb; Step 3: Injection \& binding of rFabs to captured ricin (all at $50 \mathrm{nM}$ )-chain-shuffled construct (magenta), 14F11 (blue), 9C3 (orange) and $8 \mathrm{G} 2 \mathrm{rFab}$ (black, negative control showing no binding to captured ricin).

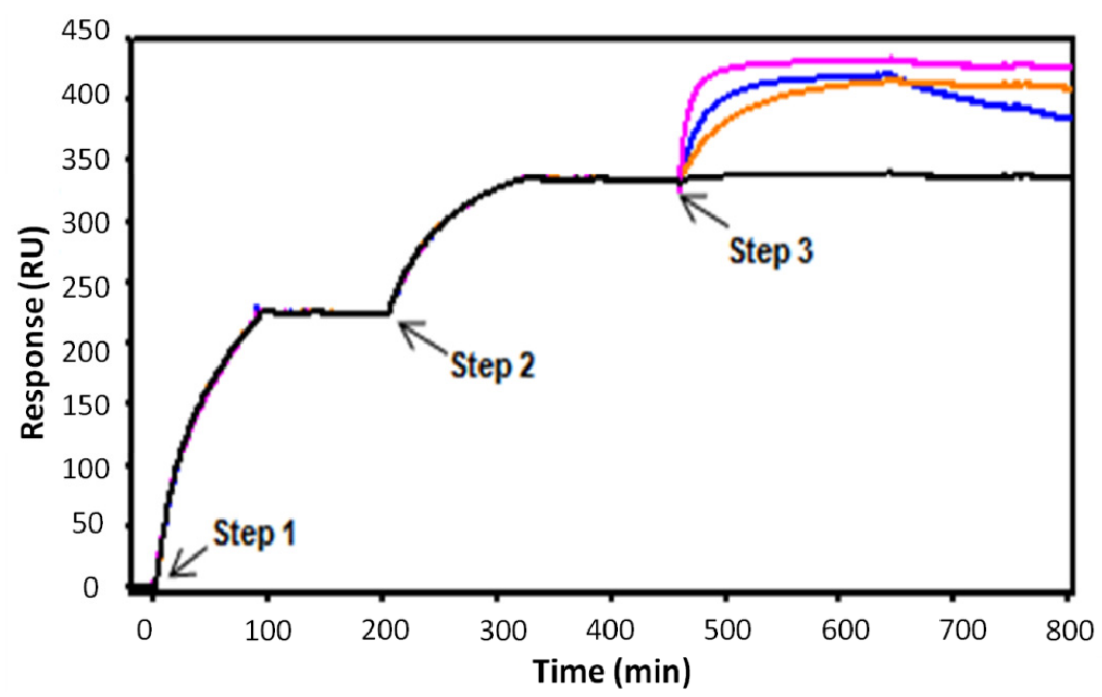

Ricin-toxicity inhibition assay showed the significantly improved binding efficacy of this chain-shuffled rFab construct. Based on our SPR measurements we concluded that the difference in the level on ricin-toxicity inhibition between the 14F11, 9C3 and chained-shuffled rFabs was predominantly due to differences in dissociation rates, with the chain-shuffled rFab having the slowest $\mathrm{k}_{\mathrm{d}}$ and consequently displaying the best inhibition properties. Recently, although through more 
sophisticated means, an increased affinity of a chimeric anti-ricin antibody C4C13 was achieved through structure based maturation [28]. Vance et al. [29] used a stepwise approach to engineer single-chain camelid $\mathrm{V}_{\mathrm{H}}$ domains to enhance ricin toxin-neutralizing antibodies. Quite clearly, a slower dissociation parameter correlates with a more stable antibody-ricin complex and consequently a decreased probability of ricin toxicity [30].

\section{Experimental}

\subsection{Ricin and Chemical Reagents}

Ricin toxin, RTA and RTB were obtained from Sigma-Aldrich (NSW, Australia). The amount of ricin toxin maintained in the laboratory was less than $5 \mathrm{mg}$ and therefore exempt from SSBA registration with the Australian government. Biacore T100 reagents were from GE-Healthcare (Uppsala, Sweden). ProteOn XPR36 biosensor reagents were from Bio-Rad (Hercules, CA, USA). Oligonucleotide primers (Table 3) were purchased from Geneworks (SA, Australia).

Table 3. Oligonucleotide primers.

\begin{tabular}{cc}
\hline Primer designation & Sequence (5'-3') \\
\hline A1437 & CAGGTCACTGTCACTGGCTCAG \\
A1436 & CTTCCACTTGACATTGATGTCTTTG \\
Poly-C anchor sense & ATCGATGAATTCGGATCCCCCCCCCCCCCCCC \\
A1706 & TGCAGAGACGGTGACCAGAGTCCCTTGGCCCCA \\
A1713 & CAGCCGGCCATGGCTGAGGTCCAGCTGCAGCAG \\
9 C3-K5' & GACGCCGATATCGATGACCCAAACTCCACT \\
9 C3-K3' & TTTTATCTCGAGCTTGGTCCCCCCGCCGAA \\
15C5-K5' & CAGGCCGATATCGTGATGACCCAAACTCCA \\
14F11-K3' & TTTCAGCTCGAGCTTGGTCCCAGCACCGAA \\
\hline
\end{tabular}

\subsection{Cultivation of Hybridoma Cell Lines and Production of mAbs}

Murine hybridoma cell lines producing antibody (all $\mathrm{IgG} 1 / \kappa)$ directed against ricin were adapted to defined hybridoma serum-free medium (Invitrogen, CA, USA) containing ciprofloxacin and grown at $37{ }^{\circ} \mathrm{C}$ under a $10 \% \mathrm{CO}_{2}$ humidified atmosphere. On the final day of incubation the supernatant was collected for purification.

\subsection{Purification of $m A b s$}

Monoclonal antibodies in serum-free hybridoma supernatants were passed through a $0.22 \mu \mathrm{m}$ filter and applied to a Prosep-vA column (Millipore, MA, USA). After washing with phosphate-buffered saline $(1 \times \mathrm{PBS})$, bound $\mathrm{mAb}$ was eluted with $0.2 \mathrm{M}$ glycine $\mathrm{pH} 2.0$, neutralized with $1 \mathrm{M}$ Tris, $\mathrm{pH} 8.0$ and dialysed against $1 \times$ PBS containing $0.02 \%(\mathrm{w} / \mathrm{v})$ sodium azide. Purity of the mAb preparations was determined by SDS-PAGE using a $10 \%$ NuPAGE $^{\circledR}$ Novex Bis-Tris gel (Invitrogen) and by size exclusion chromatography using either a Superdex $200 \mathrm{HR}$ 10/30 column (GE Healthcare) at a flow rate of $0.5 \mathrm{~mL} / \mathrm{min}$ or a BioSep-S2000 column (Phenomenex, CA, USA) at a flow rate of $1 \mathrm{~mL} / \mathrm{min}$. 
Columns were calibrated with Bio-Rad Gel Filtration Standard proteins. The concentration of purified mAbs was determined by absorbance spectroscopy [31].

\subsection{Cloning and Sequencing of Antibody Variable Regions}

Anti-ricin hybridoma cell lines [24] were used as sources for the preparation of $V_{H}$ and $V_{L} c D N A$ gene fragments. The method of Gilliland et al. [32] was adapted for the extraction of RNA and subsequent cDNA synthesis. Total cellular RNA was extracted from $5 \times 10^{6}$ hybridoma cells using TRIzol reagent (Invitrogen) and poly- $\mathrm{A}^{+}$RNA was isolated from total cellular RNA employing the Oligotex mRNA mini kit (Qiagen, Vic., Australia). Single-stranded (ss) cDNA was produced by reverse-transcription of RNA using the Omniscript reverse transcriptase kit (Qiagen). Reactions contained $500 \mathrm{ng}$ of poly- $\mathrm{A}^{+} \mathrm{RNA}$ and $10 \mathrm{pmol}$ of isotype-specific anti-sense oligonucleotide primer (A1437 for CH1- $\gamma 1$ and A1436 for CL- $\kappa$ cDNA). A poly-G tail was appended to the 3'-end of ss-cDNA using terminal transferase (NEB, MA, USA). Double-stranded cDNA was generated by PCR using Vent polymerase (NEB) with the poly-C anchor and $\mathrm{C}_{\mathrm{H}^{-}} \gamma 1$ or $\mathrm{C}_{\mathrm{L}}-\kappa$ specific primers. PCR cycling consisted: 40 cycles of 60 -s at $94{ }^{\circ} \mathrm{C}, 30$-s at $55{ }^{\circ} \mathrm{C}$ and 30 -s at $72{ }^{\circ} \mathrm{C}$. PCR products were resolved by agarose gel electrophoresis and subcloned into PCR-script Amp vector (Stratagene, CA, USA). The VH and VL genes were sequenced and aligned using Clone Manager 9 Professional Edition. The GenBank accession numbers for anti-ricin mAb VH and VL sequences are: 7G12-FN686796

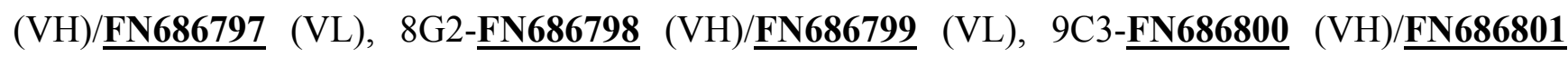
(VL), 11D7-FN686802 $(\mathrm{VH})$ / $\underline{\mathbf{F N 6 8 6 8 0 3}}$ (VL), 14F11-

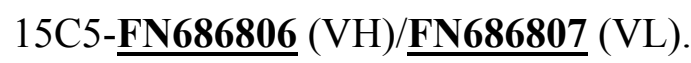

\subsection{Plasmid Vector Construction, Expression and Purification of Anti-Ricin rFabs}

The genes encoding recombinant anti-ricin Fabs were cloned into the pGC plasmid [33] as shown in Figure 4. Briefly, a rFab expression cassette (synthesized by Genscript, NJ, USA) containing human $\mathrm{CH} 1(\gamma 1)$ and $\mathrm{CL}(\kappa)$ gene sequence was digested with $\mathrm{NcoI}$ and NotI restriction enzymes and cloned into the corresponding sites in pGC to generate $\mathrm{pGC} /[$ huchcl]. $9 \mathrm{C} 3$ and $14 \mathrm{~F} 11 \mathrm{VH}$ and $\mathrm{VL}$ gene sequences were amplified by PCR using primers A1706/A1713 for $\mathrm{V}_{\mathrm{H}}$ and 9C3-K5'/9C3-K3' and 15C5-K5'/14F11-K3' for $\mathrm{V}_{\mathrm{L}}$. The resulting PCR products encoding $\mathrm{VH}$ and $\mathrm{VL}$ gene sequences were digested with appropriate restriction enzymes (NcoI and BstEII for $\mathrm{V}_{\mathrm{H}}$ and $E c o R \mathrm{~V} / X h o \mathrm{I}$ for $\mathrm{V}_{\mathrm{L}}$ ) and cloned into the corresponding sites in $\mathrm{pGC} /[$ huchcl] to create $\mathrm{pGC/anti-ricin} \mathrm{rFab}$ expression vectors (Figure 4).

Recombinant Fab clones were expressed as described in Dolezal et al. [34] and the resulting proteins purified from periplasmic extracts using a purification procedure described in Robert et al. [35]. Briefly, rFab proteins were affinity-purified via the construct's hexaHis tag using a 1-ml HisTrap FF cartridge (GE Healthcare) and then further purified on a cation exchange chromatography column (1-mL HiTrap SP, GE Healthcare). The eluted protein was concentrated to $>1 \mathrm{mg} / \mathrm{mL}$ and applied to a Superdex 200 HR 10/30 size exclusion column (GE Healthcare) pre-equilibrated in $1 \times$ PBS buffer. Collected Fab proteins were concentrated to $\sim 0.4-1 \mathrm{mg} / \mathrm{mL}$ using Pall Microsep centrifugal devices (Cheltenham Vic, Australia) and stored in $500 \mu \mathrm{L}$ aliquots at $-20{ }^{\circ} \mathrm{C}$. The concentration of purified $\mathrm{rFab}$ fragments was determined by absorbance spectroscopy [31]. 


\subsection{Epitope Binning Experiments}

Epitope binning analyses of anti-ricin mAbs was performed using a ProteOn sandwich assay described previously [36]. The ProteOn XPR36 array biosensor uses surface plasmon resonance (SPR) to monitor the interaction between immobilized ligands and injected analytes in real-time [37]. Six mAbs previously shown to bind ricin (8G2, 14F11, 9C3, 11D7, 15C5 and 7G12) were immobilized onto six channels of a GLM chip in the vertical (ligand) direction by employing a three step process. Briefly, six flow cells were activated in parallel for 5 min with a freshly mixed solution of $10 \mathrm{mM}$ EDC in $2.5 \mathrm{mM}$ sulfo-NHS. Antibodies were then coupled to the chip at a concentration of $100 \mu \mathrm{g} / \mathrm{mL}$ in $10 \mathrm{mM}$ sodium acetate, $\mathrm{pH} 4.5$ for $5 \mathrm{~min}$. Excess reactive succinimide ester groups were blocked with $1 \mathrm{M}$ ethanolamine $\mathrm{pH} 8.5$ for $5 \mathrm{~min}$. Final mean levels of immobilized mAbs ranged from 8705 to $3505 \mathrm{RU}$. Ricin was injected at $50 \mathrm{nM}$ over the immobilized mAbs, also in the vertical (ligand) direction. Following rotation of the fluidics, mAbs $(100 \mathrm{nM})$ were injected in separate channels in the horizontal (analyte) direction and binding to ricin was monitored over time.

\subsection{Kinetic Binding Analysis of $m A b s$}

Biacore T100 SPR instrument [38] was utilized to measure the binding interactions of mAbs with ricin. Immobilization and binding experiments were performed in HBS-EP+ running buffer $(10 \mathrm{mM}$ HEPES pH 7.5, $150 \mathrm{mM} \mathrm{NaCl}, 3 \mathrm{mM}$ EDTA, 0.05\% (v/v) Tween 20) at $25{ }^{\circ} \mathrm{C}$. Approximately 2000 $\mathrm{RU}\left(1 \mathrm{RU}=1 \mathrm{pg}\right.$ of protein $/ \mathrm{mm}^{2}$ ) of rabbit anti-mouse IgG, Fc specific polyclonal antibody (RAM Fc, GE Healthcare) was coupled to a CM5 chip using amine coupling chemistry as described by the supplier (GE Healthcare). Approximately $180 \mathrm{RU}$ and $300 \mathrm{RU}$ of RAM Fc was captured for RT and RTA/RTB kinetic analyses respectively with a contact time of $180-\mathrm{s}$ and flow rate of $5 \mu \mathrm{L} / \mathrm{min}$. Ricin concentrations (diluted two-fold from $50 \mathrm{nM}$ to $1.56 \mathrm{nM}$ ) or RTA/RTB (100 nM to $2 \mathrm{nM}$ ) were each injected over the captured IgG at a flow rate of $30 \mu \mathrm{L} / \mathrm{min}$ and contact time of 240 -s (RT) or $300-\mathrm{s}$ (RTA and RTB) and a dissociation time of 300-s. The sensor surface was regenerated between each binding reaction with $10 \mathrm{mM}$ glycine- $\mathrm{HCl} \mathrm{pH} 1.5$ with a flow rate of $30 \mu \mathrm{L} / \mathrm{min}$ and a contact time of 60-s. Binding data were processed and analyzed using Biacore T100 evaluation software and fit globally to a $1: 1$ binding model, $\mathrm{A}+\mathrm{B}=\mathrm{AB}$, where $\mathrm{A}$ represents the injected analyte, $\mathrm{B}$ is the immobilized ligand, and $\mathrm{AB}$ is the analyte/ligand complex formed during the reaction.

\subsection{Kinetic Binding Analysis of rFabs}

Recombinant Fab binding analyses were performed with ricin immobilized on the CM5 chip surface. Ricin was manually immobilized to the chip using a standard amine coupling chemistry method as described by instrument manufacturer (GE Healthcare). The carboxymethyl surface of the CM5 chip was activated for $7 \mathrm{~min}$ at a flow rate of $10 \mu \mathrm{L} / \mathrm{min}$ using a 1:1 ratio of $0.4 \mathrm{M}$ EDC and $0.1 \mathrm{M}$ NHS. Ricin was diluted to $3.4 \mu \mathrm{g} / \mathrm{mL}$ in $10 \mathrm{mM}$ sodium acetate $\mathrm{pH} 5.0$ and gradually injected over the surface at a flow rate of $5 \mu \mathrm{L} / \mathrm{min}$ until $100 \mathrm{RU}$ of RT was immobilized. Excess

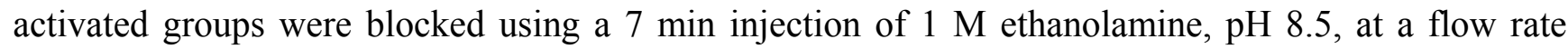
of $10 \mu \mathrm{L} / \mathrm{min}$. $\mathrm{rFab}$ at different concentrations were sequentially injected over immobilized ricin at a flow rate of $30 \mu \mathrm{L} / \mathrm{min}$, contact time of 400 -s and dissociation time of 900 -s. The sensor surface was 
regenerated between each binding event with $90 \mathrm{mM}$ phosphoric acid with a flow rate of $30 \mu \mathrm{L} / \mathrm{min}$ and contact time of 15 -s. To calculate kinetic parameters of the ricin/rFab interactions, data from each experiment were processed and globally fit to a 1:1 binding model.

\subsection{Antibody Neutralization of Ricin-Mediated Cytotoxicity}

Small airway epithelial (SAE, Lonza Australia) human lung cells were grown in small airway growth medium (SAGM, Lonza) at $37{ }^{\circ} \mathrm{C}$ with $5 \% \mathrm{CO}_{2}$. Cells were seeded in 96-well trays at a density of $1 \times 10^{4}$ per well and incubated overnight. Antibodies were diluted as required in SAGM containing $10 \mathrm{pM}$ ricin and allowed to stand at room temperature for $15 \mathrm{~min}$. Wells containing SAE cells were exposed to $100 \mu \mathrm{L}$ of the antibody-ricin mixture in triplicate for $24 \mathrm{~h}$ at $37^{\circ} \mathrm{C}$. Cells were washed twice with $1 \times$ PBS and cell viability was measured using a neutral red (NR) assay in which cells were stained with $50 \mu \mathrm{g} / \mathrm{mL}$ NR in SAGM at $37{ }^{\circ} \mathrm{C}$ for $3 \mathrm{~h}$. Cells were subsequently washed twice with $1 \times$ PBS, solubilized with $3 \mathrm{mM} \mathrm{HCl}$ in DMSO for $1 \mathrm{~h}$ and absorbance was measured at $540 \mathrm{~nm}$. Means were normalized against cells treated with ricin only (no antibody) and expressed as a percentage of the negative control (cells only).

\section{Conclusions}

To develop sensitive and rapid ricin detection methods, high-affinity mAbs such as those discussed in this study are needed. Ideally, antibodies that bind to different epitopes on either the A or B subunit are required for efficient detection of ricin. Anderson et al. [22] reported on high affinity sdAbs against both RTA and RTB and their combined use in detection platforms that included sandwich ELISA and Luminex immunoassay. From the panel of six antibodies evaluated in this study, three epitopes, two from the B subunit and one for the A subunit, were identified. Furthermore, we have identified a best antibody combination for ricin detection, whereby the two highest affinity antibodies-7G12 (specific to subunit A) and the chain-shuffled 14F11/9C3 (subunit B) antibodies could be used either as primary capture and/or secondary detection reagents. Their slow dissociation kinetics, in particular, should prove useful not only in the detection of ricin but also, after appropriate reformatting, for prevention and/or treatment of ricin intoxication.

\section{Acknowledgments}

We thank Phillip Strike for N-terminal sequencing and Deborah Shapira for culturing of the hybridoma cell lines.

\section{Authors Contributions}

Conceived and designed the experiments: MC, MA, DP, SN and OD. Performed the experiments: MC, CD, RR, DC, LP-B, AR, MH and OD. Analysed the data: MC, DC, MH and OD. Wrote the paper: $\mathrm{MC}, \mathrm{CD}, \mathrm{SN}$ and $\mathrm{OD}$.

\section{Conflicts of Interest}

The authors declare no conflict of interest. 


\section{References}

1. Foxwell, B.M.; Detre, S.I.; Donovan, T.A.; Thorpe, P.E. The use of anti-ricin antibodies to protect mice intoxicated with ricin. Toxicology 1985, 34, 79-88.

2. Guo, J.W.; Shen, B.F.; Feng, J.N.; Sun, Y.X.; Yu, M.; Hu, M.R. A novel neutralizing monoclonal antibody against cell-binding polypeptide of ricin. Hybridoma (Larchmt) 2005, 24, 263-266.

3. Olsnes, S.; Pihl, A. Different biological properties of the two constituent peptide chains of ricin, a toxic protein inhibiting protein synthesis. Biochemistry 1973, 12, 3121-3126.

4. Baenziger, J.U.; Fiete, D. Structural determinants of ricinus communis agglutinin and toxin specificity for oligosaccharides. J. Biol. Chem. 1979, 254, 9795-9799.

5. Alami, M.; Taupiac, M.P.; Beaumelle, B. Ricin-binding proteins along the endocytic pathway: The major endosomal ricin-binding protein is endosome-specific. Cell Biol. Int. 1997, 21, 145-150.

6. Lord, J.M.; Deeks, E.; Marsden, C.J.; Moore, K.; Pateman, C.; Smith, D.C.; Spooner, R.A.; Watson, P.; Roberts, L.M. Retrograde transport of toxins across the endoplasmic reticulum membrane. Biochem. Soc. Trans. 2003, 31, 1260-1262.

7. Sandvig, K.; Ryd, M.; Garred, O.; Schweda, E.; Holm, P.K.; van Deurs, B. Retrograde transport from the golgi complex to the er of both shiga toxin and the nontoxic shiga b-fragment is regulated by butyric acid and camp. J. Cell Biol. 1994, 126, 53-64.

8. Mlsna, D.; Monzingo, A.F.; Katzin, B.J.; Ernst, S.; Robertus, J.D. Structure of recombinant ricin a chain at 2.3 a. Protein Sci. 1993, 2, 429-435.

9. Chen, X.Y.; Link, T.M.; Schramm, V.L. Ricin a-chain: Kinetics, mechanism, and rna stem-loop inhibitors. Biochemistry 1998, 37, 11605-11613.

10. Endo, Y.; Mitsui, K.; Motizuki, M.; Tsurugi, K. The mechanism of action of ricin and related toxic lectins on eukaryotic ribosomes. The site and the characteristics of the modification in $28 \mathrm{~s}$ ribosomal rna caused by the toxins. J. Biol. Chem. 1987, 262, 5908-5912.

11. Pincus, S.H.; Smallshaw, J.E.; Song, K.; Berry, J.; Vitetta, E.S. Passive and active vaccination strategies to prevent ricin poisoning. Toxins (Basel) 2011, 3, 1163-1184.

12. McGuinness, C.R.; Mantis, N.J. Characterization of a novel high-affinity monoclonal immunoglobulin $g$ antibody against the ricin b subunit. Infect. Immun. 2006, 74, 3463-3470.

13. Reisler, R.B.; Smith, L.A. The need for continued development of ricin countermeasures. Adv. Prev. Med. 2012, 2012, 149737.

14. Smallshaw, J.E.; Vitetta, E.S. A lyophilized formulation of rivax, a recombinant ricin subunit vaccine, retains immunogenicity. Vaccine 2010, 28, 2428-2435.

15. Neal, L.M.; O'Hara, J.; Brey, R.N.; Mantis, N.J. A monoclonal immunoglobulin g antibody directed against an immunodominant linear epitope on the ricin a chain confers systemic and mucosal immunity to ricin. Infect. Immun. 2010, 78, 552-561.

16. Prigent, J.; Panigai, L.; Lamourette, P.; Sauvaire, D.; Devilliers, K.; Plaisance, M.; Volland, H.; Creminon, C.; Simon, S. Neutralising antibodies against ricin toxin. PLoS One 2011, 6, e20166.

17. Hu, W.G.; Yin, J.; Chau, D.; Negrych, L.M.; Cherwonogrodzky, J.W. Humanization and characterization of an anti-ricin neutralization monoclonal antibody. PLoS One 2012, 7, e45595.

18. Sheridan, C. Fresh from the biologic pipeline-2009. Nat. Biotechnol. 2010, 28, 307-310. 
19. Kim, S.J.; Park, Y.; Hong, H.J. Antibody engineering for the development of therapeutic antibodies. Mol. Cells 2005, 20, 17-29.

20. Pelat, T.; Hust, M.; Hale, M.; Lefranc, M.P.; Dübel, S.; Thullier, P. Isolation of a human-like antibody fragment (scfv) that neutralizes ricin biological activity. BMC Biotechnol. 2009, 9, 60.

21. Anderson, G.P.; Liu, J.L.; Hale, M.L.; Bernstein, R.D.; Moore, M.; Swain, M.D.; Goldman, E.R. Development of antiricin single domain antibodies toward detection and therapeutic reagents. Anal. Chem. 2008, 80, 9604-9611.

22. Anderson, G.P.; Bernstein, R.D.; Swain, M.D.; Zabetakis, D.; Goldman, E.R. Binding kinetics of antiricin single domain antibodies and improved detection using a $\mathrm{b}$ chain specific binder. Anal. Chem. 2010, 82, 7202-7207.

23. Walper, S.A.; Brozozog Lee, P.A.; Goldman, E.R.; Anderson, G.P. Comparison of single domain antibody immobilization strategies evaluated by surface plasmon resonance. J. Immunol. Methods 2013, 388, 68-77.

24. Dertzbaugh, M.T.; Rossi, C.A.; Paddle, B.M.; Hale, M.; Poretski, M.; Alderton, M.R. Monoclonal antibodies to ricin: In vitro inhibition of toxicity and utility as diagnostic reagents. Hybridoma (Larchmt) 2005, 24, 236-243.

25. Tran, H.; Leong, C.; Loke, W.K.; Dogovski, C.; Liu, C.Q. Surface plasmon resonance detection of ricin and horticultural ricin variants in environmental samples. Toxicon 2008, 52, 582-588.

26. Butler, J.E.; Navarro, P.; Sun, J. Adsorption-induced antigenic changes and their significance in elisa and immunological disorders. Immunol. Invest. 1997, 26, 39-54.

27. Anderson, G.P.; Glaven, R.H.; Algar, W.R.; Susumu, K.; Stewart, M.H.; Medintz, I.L.; Goldman, E.R. Single domain antibody-quantum dot conjugates for ricin detection by both fluoroimmunoassay and surface plasmon resonance. Anal. Chim. Acta 2013, 786, 132-138.

28. Luo, L.; Luo, Q.; Guo, L.; Lv, M.; Lin, Z.; Geng, J.; Li, X.; Li, Y.; Shen, B.; Qiao, C.; et al. Structure-based affinity maturation of a chimeric anti-ricin antibody c4c13. J. Biomol. Struct. Dyn. 2014, in press.

29. Vance, D.J.; Tremblay, J.M.; Mantis, N.J.; Shoemaker, C.B. Stepwise engineering of heterodimeric single domain camelid vhh antibodies that passively protect mice from ricin toxin. J. Biol. Chem. 2013, 288, 36538-36547.

30. Song, K.; Mize, R.R.; Marrero, L.; Corti, M.; Kirk, J.M.; Pincus, S.H. Antibody to ricin a chain hinders intracellular routing of toxin and protects cells even after toxin has been internalized. PLoS One 2013, 8, e62417.

31. Gill, S.C.; von Hippel, P.H. Calculation of protein extinction coefficients from amino acid sequence data. Anal. Biochem. 1989, 182, 319-326.

32. Gilliland, L.K.; Norris, N.A.; Marquardt, H.; Tsu, T.T.; Hayden, M.S.; Neubauer, M.G.; Yelton, D.E.; Mittler, R.S.; Ledbetter, J.A. Rapid and reliable cloning of antibody variable regions and generation of recombinant single chain antibody fragments. Tissue Antigens 1996, 47, 1-20.

33. Coia, G.; Ayres, A.; Lilley, G.G.; Hudson, P.J.; Irving, R.A. Use of mutator cells as a means for increasing production levels of a recombinant antibody directed against hepatitis b. Gene 1997, 201, 203-209. 
34. Dolezal, O.; Pearce, L.A.; Lawrence, L.J.; McCoy, A.J.; Hudson, P.J.; Kortt, A.A. Scfv multimers of the anti-neuraminidase antibody nc10: Shortening of the linker in single-chain fv fragment assembled in $\mathrm{v}(\mathrm{l})$ to $\mathrm{v}(\mathrm{h})$ orientation drives the formation of dimers, trimers, tetramers and higher molecular mass multimers. Protein Eng. 2000, 13, 565-574.

35. Robert, R.; Streltsov, V.A.; Newman, J.; Pearce, L.A.; Wark, K.L.; Dolezal, O. Germline humanization of a murine abeta antibody and crystal structure of the humanized recombinant fab fragment. Protein Sci. 2010, 19, 299-308.

36. Abdiche, Y.; Malashock, D.; Pinkerton, A.; Pons, J. Determining kinetics and affinities of protein interactions using a parallel real-time label-free biosensor, the octet. Anal. Biochem. 2008, 377, 209-217.

37. Bravman, T.; Bronner, V.; Lavie, K.; Notcovich, A.; Papalia, G.A.; Myszka, D.G. Exploring "one-shot" kinetics and small molecule analysis using the proteon xpr36 array biosensor. Anal. Biochem. 2006, 358, 281-288.

38. Papalia, G.A.; Baer, M.; Luehrsen, K.; Nordin, H.; Flynn, P.; Myszka, D.G. High-resolution characterization of antibody fragment/antigen interactions using biacore t100. Anal. Biochem. 2006, 359, 112-119.

(C) 2014 by the authors; licensee MDPI, Basel, Switzerland. This article is an open access article distributed under the terms and conditions of the Creative Commons Attribution license (http://creativecommons.org/licenses/by/3.0/). 